Check for updates

Cite this: Chem. Sci., 2019, 10, 7456

๑ All publication charges for this article have been paid for by the Royal Society of Chemistry

Received 8th March 2019

Accepted 19th June 2019

DOI: $10.1039 /$ c9sc01165j

rsc.li/chemical-science

\title{
Selective coordination of three transition metal ions within a coiled-coil peptide scaffold $\dagger$
}

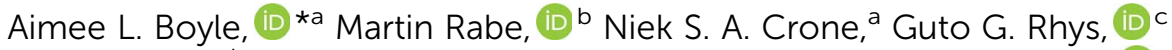 \\ Nicolas Soler, ${ }^{d}$ Patrick Voskamp, ${ }^{a}$ Navraj S. Pannu ${ }^{a}$ and Alexander Kros (D) ${ }^{a}$
}

\begin{abstract}
Designing peptides that fold and assemble in response to metal ions tests our understanding of how peptide folding and metal binding influence one another. Here, histidine residues are introduced into the hydrophobic core of a coiled-coil trimer, generating a peptide that self-assembles upon the addition of metal ions. HisAD, the resulting peptide, is unstructured in the absence of metal and folds selectively to form an $\alpha$-helical construct upon complexation with $\mathrm{Cu}(॥)$ and $\mathrm{Ni}(॥)$ but not $\mathrm{Co}(॥)$ or $\mathrm{Zn}(॥)$. The structure, and metal-binding ability, of HisAD is probed using a combination of circular dichroism (CD) spectroscopy, analytical ultracentrifugation (AUC), nuclear magnetic resonance (NMR) spectroscopy and $\mathrm{X}$-ray crystallography. These show the peptide is trimeric and binds to both $\mathrm{Cu}(॥)$ and $\mathrm{Ni}\left({ }^{\prime}\right)$ in a $1: 1$ ratio with the histidine residues involved in the metal coordination, as designed. The X-ray crystal structure of the HisAD-Cu(॥) complex reveals the trimeric HisAD peptide coordinates three $\mathrm{Cu}(\|)$ ions; this is the first example of such a structure. Additionally, HisAD demonstrates an unprecedented discrimination between transition metal ions, the basis of which is likely to be related to the stability of the peptidemetal complexes formed.
\end{abstract}

\section{Introduction}

A fundamental aim of metalloprotein design is to understand how metal-binding and protein folding affect each other and to use this knowledge to produce novel metallopeptides, often utilising minimal scaffolds.

One scaffold that has been widely employed for this purpose is the $\alpha$-helical coiled coil. Canonical coiled coils are formed when two or more $\alpha$-helices interact in a specific manner, known as 'knobs-into-holes' packing. ${ }^{1}$ Most coiled coils also have a repeating sequence pattern known as a 'heptad repeat,' which is given the nomenclature $a b c d e f g$, with hydrophobic residues found at the ' $a$ ' and ' $d$ ' positions and polar residues occupying the other positions. ${ }^{2,3}$ These characteristics have enabled researchers to devise rules that allow coiled coils with prescribed oligomer states and orientations to be reliably designed, ${ }^{\mathbf{4} 5}$ making them attractive candidates for metallopeptide design.

${ }^{a}$ Leiden Institute of Chemistry, Leiden University, Einsteinweg 55, 2333 CC Leiden, The Netherlands. E-mail: a.l.boyle@chem.leidenuniv.nl

${ }^{b}$ Max-Planck-Institut für Eisenforschung GmbH, Max-Planck-Straße 1, 40237 Düsseldorf, Germany

${ }^{c}$ School of Chemistry, University of Bristol, Cantock's Close, Bristol, BS8 1TS, UK ${ }^{d}$ Structural Biology Unit, Institute of Molecular Biology of Barcelona (IBMB-CSIC), Baldiri Reixac 15, 08028 Barcelona, Spain

$\dagger$ Electronic supplementary information (ESI) available. See DOI: $10.1039 / \mathrm{c} 9 \mathrm{sc} 01165 \mathrm{j}$
The most common examples of metal-binding coiled coils substitute hydrophobic residues at the ' $a$ ' and ' $d$ ' positions with amino acids capable of coordinating metal ions, and this often results in the binding of a single metal ion in the hydrophobic core of the coiled coil. The Pecoraro lab in particular have presented multiple designs of this type, utilising their TRI series of peptides, ${ }^{6-8}$ so called as they form trimeric coiled coils, and variants of $\alpha 3 \mathrm{D} ;^{9-12}$ a single-chain three-helix bundle originally developed by the DeGrado lab. ${ }^{13}$ The Tanaka lab have also made significant contributions to this field with their trimeric IZ peptide, which contains two histidine residues and binds $\mathrm{Co}(\mathrm{II})$, $\mathrm{Cu}(\mathrm{II}), \mathrm{Ni}(\mathrm{II})$ and $\mathrm{Zn}(\mathrm{II}),{ }^{\mathbf{1 4}}$ and their tetrameric AM2D and AM2E peptides which also bind $\mathrm{Cu}(\mathrm{II})$ and $\mathrm{Zn}(\mathrm{II}){ }^{\mathbf{1 5}}$

Other notable examples of coiled-coil-based peptides which bind a single metal ion include a homodimeric Cd(II)-binding mimic of the protein rubredoxin from the Ogawa lab; ${ }^{16}$ a $\mathrm{Zn}$ (II)binding heterodimer from the Jerala lab; ${ }^{17}$ and a $\mathrm{Zn}$ (II) binding tetrameric helical bundle from the Kuhlman and Hilvert labs. ${ }^{18}$ Additionally, the Peacock lab has generated a trimeric coiledcoil peptide that employs asparagine and aspartic acid residues to bind lanthanides. ${ }^{19}$

While peptides incorporating a single metal-binding site are now designed with relative ease, coordination of multiple metal ions is more challenging. DeGrado and colleagues have had notable success in this endeavour creating Due Ferri, a fourhelix bundle of which many variants have been presented; ${ }^{20-23}$ a notable recent derivative is capable of supporting a tetranuclear $\mathrm{Zn}$ (II) cluster. ${ }^{24}$ The Allen lab has also designed four-helix 
bundle peptides that are capable of supporting multinuclear metal-binding sites, examples of metal ions bound include both dinuclear $\mathrm{Mn}(\mathrm{II}),{ }^{25}$ and $\mathrm{Cu}(\mathrm{II}),{ }^{26}$ whilst a similar design which also binds $\mathrm{Cu}(\mathrm{II})$ has been presented by the Tanaka lab. ${ }^{27}$

The Ogawa lab has created a tetrameric coiled-coil peptide which binds a $\mathrm{Cu}_{4} \mathrm{~S}_{4}$ cluster; ${ }^{28}$ interestingly the same peptide was dimeric when $\mathrm{Cd}(\mathrm{II})$ was bound. ${ }^{\mathbf{1 6}} \mathrm{A}$ second peptide that possessed a multinuclear $\mathrm{Cd}$ (II) centre was also developed but the crystal structure revealed a distorted peptide backbone. ${ }^{29}$ These examples in particular highlight the delicate interplay between peptide folding and metal coordination and how the choice of metal can affect how the peptide assembles.

In addition to the aforementioned four-helix bundles, trimeric peptides have also been employed to bind multiple metal ions: one such structure incorporates two $4 \mathrm{Fe}-4 \mathrm{~S}$ clusters ${ }^{30}$ and the Tanaka, Pecoraro, and Peacock labs have all designed trimeric peptides capable of simultaneously coordinating two different metals at structurally different sites within the same scaffold. ${ }^{31-34}$

Some of these designs have also begun to address the issue of metal selectivity; a concept which is critically important for developing effective biosensing or purification devices for example. At the most fundamental level, selectivity can be achieved by designing metal-binding sites with different amino acids, as different metals have preferences for different coordinating ligands. Selectivity can also be achieved by limiting the number of residues available for coordination to the metal of interest, thus selecting for metals that prefer lower coordination numbers. ${ }^{35,36}$ Alternatively, selectivity can be obtained by choosing which position of the heptad repeat metal-binding residues are incorporated into; it has been demonstrated that Cd(II) produces higher affinity complexes when bound at an ' $a$ ' position of the heptad repeat. ${ }^{37}$

In this article we redesign a trimeric coiled-coil scaffold by mutating isoleucine residues within the hydrophobic core to histidine, with the aim of creating a peptide capable of binding transition metal ions. The resulting peptide is unfolded in the absence of metal ions, but folds and self-assembles in the presence of $\mathrm{Cu}$ (II) and $\mathrm{Ni}(\mathrm{II})$, but not $\mathrm{Co}(\mathrm{II})$ or $\mathrm{Zn}$ (II). A combination of circular dichroism (CD) spectroscopy, analytical ultracentrifugation (AUC), and nuclear magnetic resonance (NMR) spectroscopy were employed to gain further information regarding peptide secondary structure and stability, oligomeric state, and the nature of the metal-binding site. The X-ray crystal structure of the peptide-Cu(II) complex was solved, which revealed a trinuclear $\mathrm{Cu}$ (II) site with the metal ions being coordinated by histidine and glutamic acid residues. To the best of our knowledge, this is the first example of a designed, $\alpha$-helical, metallopeptide that coordinates three metal ions, and that exhibits a high degree of metal-binding selectivity.

\section{Results and discussion}

\section{Peptide design}

We utilized the homotrimeric coiled-coil CC-Tri, ${ }^{4}$ as the starting point for our metallopeptide design. Histidine residues were placed at hydrophobic positions within the central heptads, generating three mutants: HisA, HisD, and HisAD, Table 1. The central heptads were chosen as the optimal sites for mutation as it has previously been shown that substituting isoleucine for polar residues within the terminal heptads leads to a loss of oligomer state specificity. ${ }^{38}$

HisA, HisD, and HisAD contain a histidine, (His, H), residue in place of an isoleucine, (Ile, I), at either the ' $d$ ' position of the second heptad (HisD), the ' $a$ ' position of the third heptad (HisA), or at both of these positions (HisAD); it is anticipated that metal ions will be coordinated by these His residues. Glutamic acid residues may also play a role in metal coordination, as has been observed for other designs. ${ }^{15,26}$

\section{Secondary structure characterization in solution}

The peptides were initially analysed using CD spectroscopy to examine their secondary structure in solution, both in the presence and absence of a variety of transition metal ions. HisA and HisD were both still folded as $\alpha$-helical species in the absence of metal ions, (Fig. S1 $\dagger$ ), although the ellipticity value at $222 \mathrm{~nm}$ was reduced compared to CC-Tri $\left(-17024 \mathrm{deg} \mathrm{cm}^{2} \mathrm{dmol}\right.$ res $^{-1}$ and $-23190 \mathrm{deg} \mathrm{cm}^{2}$ dmol $\mathrm{res}^{-1}$ for HisA and HisD respectively, compared to $-31482 \mathrm{deg} \mathrm{cm}^{2} \mathrm{dmol} \mathrm{res}^{-1}$ for CCTri, Fig. S1†). This decrease is not surprising given that there is an intrinsic energy penalty associated with including a polar residue in the hydrophobic core, especially for de novo designed sequences. $^{38}$ Addition of $\mathrm{Co}(\mathrm{II}), \mathrm{Cu}(\mathrm{II}), \mathrm{Ni}(\mathrm{II})$, or $\mathrm{Zn}$ (II) did not alter the folding of these peptides, (Fig. S1 $\dagger$ ).

HisAD, in contrast, was largely unfolded in the absence of metal species, (Fig. 1). This indicates that mutating two residues within the hydrophobic core of CC-Tri is highly destabilising, and the peptide can no longer self-assemble. Upon addition of an equimolar concentration of different transition metal ion species, it was discovered that both $\mathrm{Cu}$ (II) and $\mathrm{Ni}$ (II) could induce HisAD to fold into a helical structure, but $\mathrm{Zn}$ (II) and $\mathrm{Co}$ (II) could not. This selective, metal-induced, folding is highly intriguing as all four metal species have previously been shown to coordinate to coiled-coil peptides containing a similar arrangement of His ligands. ${ }^{\mathbf{1 4}}$ This selectivity is not likely to be a result of geometric preferences as, although each metal has preferred coordination geometries, all four metals have been shown to adopt a range of geometries in metalloproteins..$^{39,40}$ It is possible that this

Table 1 Sequences of the parent peptide CC-Tri, and His-containing mutants HisA, HisD, and HisAD

\begin{tabular}{ccc}
\hline Peptide & \multicolumn{2}{c}{ Sequence $^{a}$} \\
& gabcdef gabcdef gabcdef gabcdef \\
\hline CC-Tri & G EIAAIKQ EIAAIKK EIAAIKW EIAAIKQ GYG \\
HisA $^{b}$ & G EIAAIKQ EIAAIKK EHAAIKW EIAAIKQ GYG \\
HisD $^{b}$ & G EIAAIKQ EIAAHKK EIAAIKW EIAAIKQ GYG \\
HisAD $^{b}$ & G EIAAIKQ EIAAHKK EHAAIKW EIAAIKQ GYG \\
\hline
\end{tabular}

\footnotetext{
${ }^{a}$ The sequences are written following the characteristic heptad repeat pattern of canonical coiled coils. All peptides are acetylated at the Nterminus and amidated at the C-terminus. ${ }^{b}$ The positions of the histidine mutations are shown in red and underlined.
} 


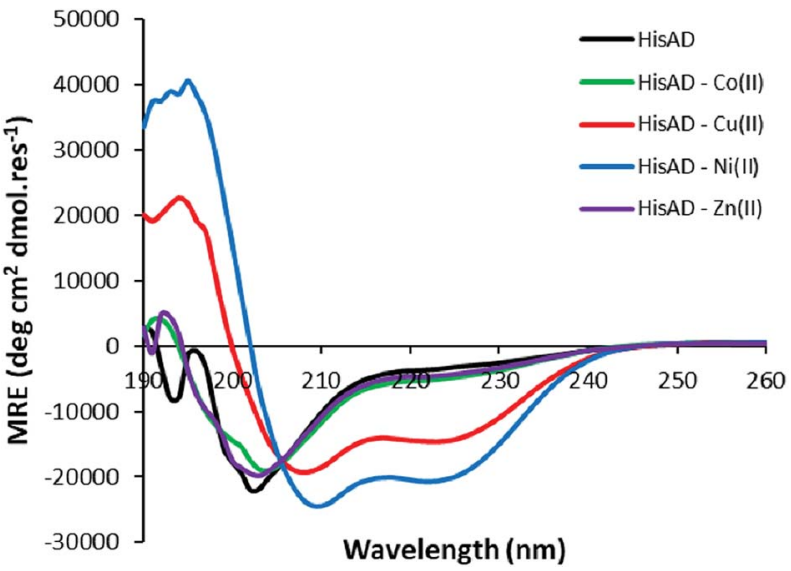

Fig. 1 CD spectra of HisAD in the absence and presence of divalent transition metal ions. Conditions: [peptide] $=100 \mu \mathrm{M}$, [metal] $=100$ $\mu \mathrm{M}, 10 \mathrm{mM}$ phosphate buffer $\mathrm{pH} 7.4,20^{\circ} \mathrm{C}$.

selectivity is a reflection of the stabilizing effects of the transition metal ions; $\mathrm{Ni}(\mathrm{II})$ and $\mathrm{Cu}$ (II) species form the most stable metalligand complexes according to the Irving-Williams series. ${ }^{41}$

\section{NMR confirms histidine residues are involved in $\mathrm{Cu}(\mathrm{II})$ and Ni(II) coordination}

To verify that the histidine residues were involved in the coordination of the metal ions, as designed, ${ }^{1} \mathrm{H}$ NMR spectra of HisAD were recorded in the absence and presence of both $\mathrm{Cu}(\mathrm{II})$ and $\mathrm{Ni}(\mathrm{II})$.

In the absence of metal, signals from the histidine protons were evident at 6.96 and 7.89 ppm, (Fig. 2, black lines, and Fig. S2 $\dagger$ ). These were assigned as being from histidine, as they were not evident in the NMR spectra of CC-Tri (Figs. S5-7†). Upon addition of 1 equivalent of $\mathrm{Cu}$ (II), the complete disappearance of the histidine $\varepsilon-\mathrm{CH}$ proton signal at $7.89 \mathrm{ppm}$ was observed, (Fig. 2A, red line and Fig. S3†). HisAD also contains tryptophan (Trp, W) and tyrosine (Tyr, Y) residues, and the paramagnetic nature of $\mathrm{Cu}$ (II) leads to significant line broadening and overlapping peaks, therefore it was difficult to determine whether the signal from the histidine $\delta$ - $\mathrm{CH}$, at $6.96 \mathrm{ppm}$, had also disappeared. A mutant of HisAD without Trp and Tyr, HisAD-WY, was therefore synthesised and the addition of 1 equivalent of $\mathrm{Cu}$ (II) lead to the disappearance of both His resonances (Fig. S8 and S9†).

Addition of Ni(II) produced a similar spectrum, (Fig. 2B, blue line and $\mathrm{S} 4 \dagger)$. The line broadening here was not as pronounced as the electron relaxation time of $\mathrm{Ni}(\mathrm{II})$ is $1-3$ orders slower than for $\mathrm{Cu}(\mathrm{II}){ }^{42}$

Whilst these spectra do not preclude the involvement of residues other than histidine coordinating to the metal ions, they do confirm that both His residues are indeed involved in coordinating both $\mathrm{Cu}(\mathrm{II})$ and $\mathrm{Ni}(\mathrm{II})$, as designed.

\section{$\mathrm{Cu}$ (II) and Ni(II) peptide complexes are trimeric in solution}

The coordination of metals to peptides has been known to affect the peptides oligomeric state, ${ }^{28,43,44}$ highlighting the
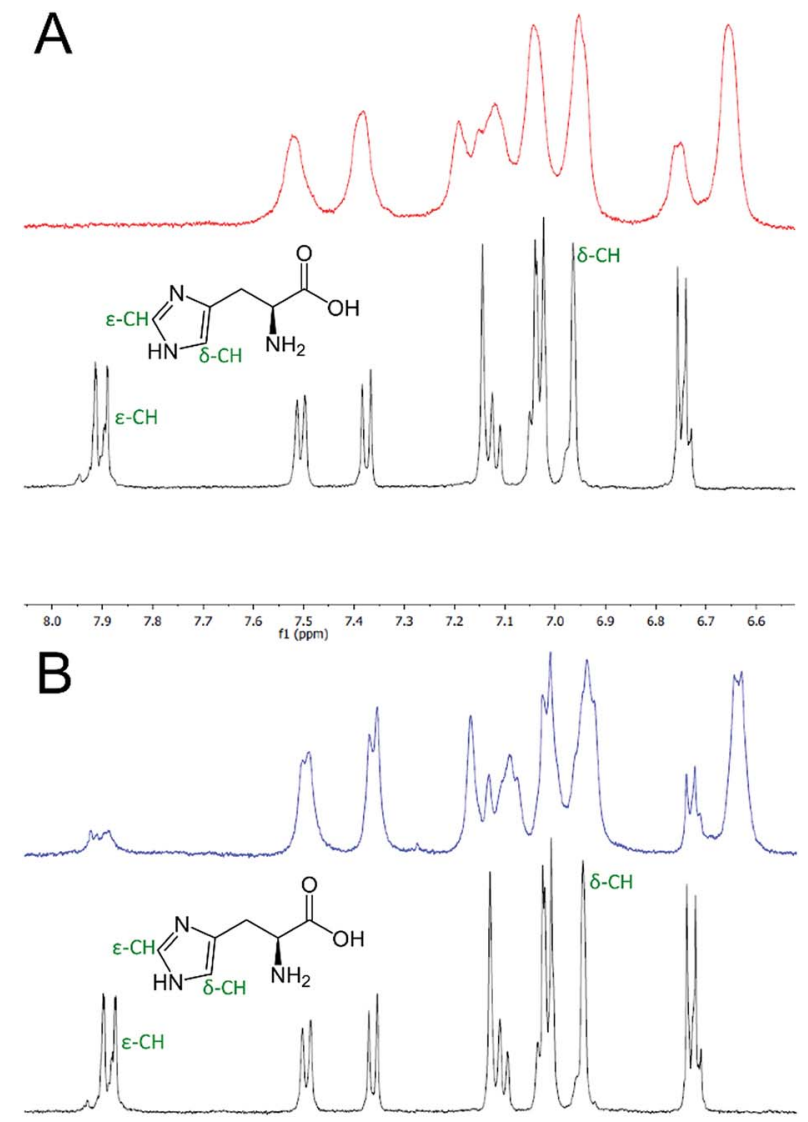

\begin{tabular}{llllllllllllllll}
\hline 8.0 & 7.9 & 7.8 & 7.7 & 7.6 & $\begin{array}{c}7.5 \\
\mathrm{f} 1\end{array}(\mathrm{ppm})$ & 7.4 & 7.3 & 7.2 & 7.1 & 7.0 & 6.9 & 6.8 & 6.7 & 6.6
\end{tabular}

Fig. 2 One-dimensional ${ }^{1} \mathrm{H}$ NMR spectra of the aromatic region of HisAD. (A) HisAD in the absence (black line) and presence (red line) of 1 equivalent of $\mathrm{Cu}\left({ }^{\prime \prime}\right)$. (B) HisAD in the absence (black line) and presence (blue line) of 1 equivalent of $\mathrm{Ni}\left({ }_{1}\right)$. The signals corresponding to the histidine protons are indicated. Conditions: [peptide] $=500 \mu \mathrm{M}$, [metal] $=500 \mu \mathrm{M}, 10 \mathrm{mM}$ deuterated phosphate buffer, pH 7.4.

delicate interplay between peptide folding and metalcoordination. AUC experiments were therefore performed to probe the oligomerization state of HisAD in the presence of $\mathrm{Cu}$ (II) and $\mathrm{Ni}$ (II). As HisAD is largely unfolded in the absence of metals, AUC experiments with apo-HisAD were not performed.

Both sedimentation velocity (SV) and sedimentation equilibrium (SE) experiments showed monodisperse assemblies were formed; only one peak was observed in the SV experiments and the SE curves fitted well to a single, ideal-species model, (Fig. S10A-D $\dagger$ ). These data indicate that HisAD forms a trimeric species in the presence of both $\mathrm{Cu}(\mathrm{II})$ and $\mathrm{Ni}(\mathrm{II})$. These results show that HisAD forms the same trimeric oligomer state in solution as the parent peptide CC-Tri, meaning that the binding of $\mathrm{Cu}$ (II) and $\mathrm{Ni}$ (II) do not influence the designed, intended, oligomeric state of HisAD. 
The X-ray crystal structure of the HisAD-Cu(II) complex reveals three $\mathrm{Cu}$ (II) ions are coordinated by the HisAD trimer

Intrigued by the metal-binding selectivity exhibited by HisAD, in combination with the knowledge that the trimeric structure of the parent peptide is retained upon binding $\mathrm{Cu}$ (II) and $\mathrm{Ni}(\mathrm{II})$, detailed structural information was highly desirable. Crystals of HisAD with both $\mathrm{Cu}(\mathrm{II})$ and $\mathrm{Ni}(\mathrm{II})$ were obtained, however only the $\mathrm{Cu}(\mathrm{II})$-containing crystals diffracted to a sufficient resolution to allow a dataset to be obtained and a structure to subsequently be solved, (Fig. 3 and Table 2).

The crystal structure of the HisAD-Cu(II) complex was solved at $2.35 \AA$ resolution. This structure revealed that the trimeric HisAD peptide coordinates three $\mathrm{Cu}$ (II) ions, (Fig. 3). This is the first example of a designed $\alpha$-helical peptide that coordinates three metal ions.
It is evident from the packing of the helices that the metal ions drive the association and organization of this complex. At the C-terminus of HisAD, the packing of the helices resembles that of the parent peptide, CC-Tri, (Fig. S11†). At the N-terminus however, the structure is splayed and the hydrophobic core is not as tightly packed; therefore SOCKET, a program that searches for knobs-into-holes interactions characteristic of coiled coils, ${ }^{45}$ only finds such interactions at the C-terminal side of the binding site. The reason for this disruption of the helix packing is due to the need for both His13 and His17 to be oriented towards the $\mathrm{Cu}(\mathrm{II})$ ion, and it is at this point that a deviation from the CC-Tri supercoiling is apparent, (Fig. S11B $\dagger$ ).

In addition to the nitrogen atoms of His13 and His17, each $\mathrm{Cu}(\mathrm{II})$ ion is additionally coordinated by both oxygen atoms of a glutamic acid residue (Glu16) from a second helix. This leads
A

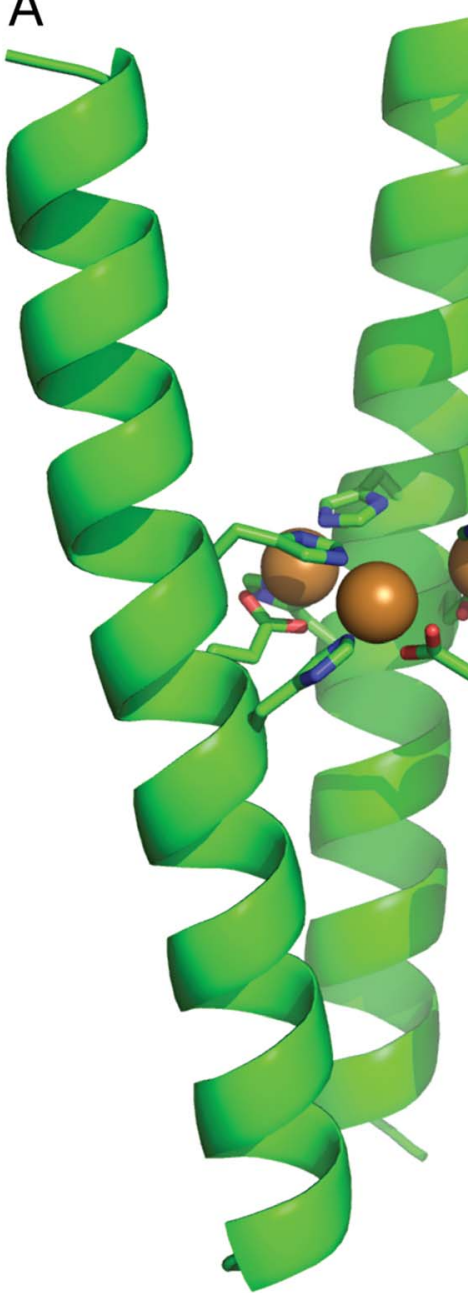

B

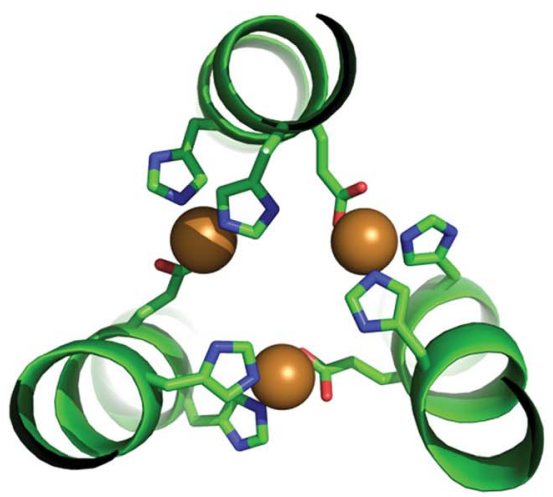

C
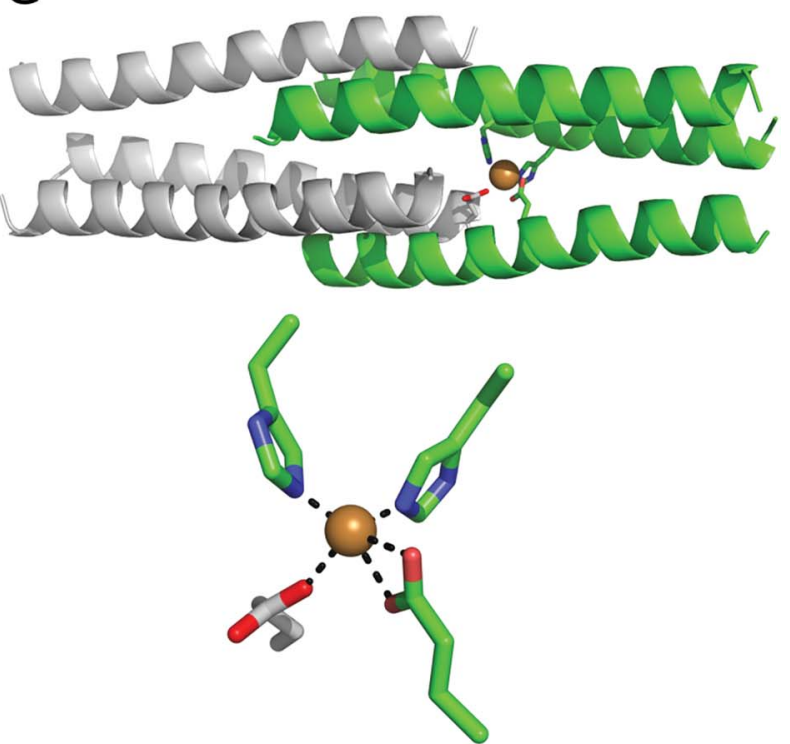

Fig. 3 X-ray crystal structure of the HisAD-Cu(II) complex, PDB ID: 6I1J. (A) Side view and; (B) top-down view. The peptide backbone is depicted in cartoon format, residues coordinating the copper ions are shown as sticks and the $\mathrm{Cu}(\mathrm{II})$ ions are rendered as spheres. In (B) the helical backbone is partially cut away for clarity. (C) In the crystal structure each $\mathrm{Cu}\left({ }^{\prime}\right)$ ion is coordinated by two histidine residues and one glutamic acid residue from one trimer, and an additional glutamic acid from a symmetry-related trimer. The top panel shows the entire structure, with only one $\mathrm{Cu}(\mathrm{II})$ ion shown for clarity. The symmetry-related trimer is coloured grey. The lower panel provides a close-up of the coordination of the Cu(II) centre. All images are generated with PyMol, for the residues shown as sticks colouring is as follows: carbon, green; oxygen, red; nitrogen, blue. $\mathrm{Cu}(I)$ ions are shown as orange spheres. 
Table 2 X-ray data collection and refinement statistics

\begin{tabular}{ll}
\hline Beamline & ID30B \\
\hline Detector & Pilatus3_6M \\
Frames & 2400 \\
Oscillation $\left(^{\circ}\right)$ & 0.15 \\
Exposure time per frame, total (s) & $0.025,60$ \\
Space group & $\mathrm{P} 6_{3} 22$ \\
& \\
Unit-cell parameters & \\
$\alpha, \beta, \gamma$ & $30.52,30.52,106.04$ \\
$a, b, c$, & $90,90,120$ \\
Resolution range $(\mathrm{A}),($ outer resolution shell) & $26.51-2.35,(2.54-2.35)$ \\
Observations & $44183(9096)$ \\
Unique reflections & $1493(293)$ \\
Completeness $(\%)$ & $99.9(100)$ \\
CC $(1 / 2)$ & $1.00(0.92)$ \\
$R_{\text {pim }}(\%)$ & $0.011(0.424)$ \\
$\langle I / \sigma(I)\rangle$ & $65.3(1.9)$ \\
Multiplicity & $29.6(31.0)$ \\
$R$ factor $(\%)$ & 26.7 \\
$R$ complete $(\%)$ & 25.5 \\
Bond lengths $(\AA)$ & 0.015 \\
Bond angles $\left({ }^{\circ}\right)$ & 1.705 \\
Ramachandran preferred regions & 100 \\
Allowed regions & 0 \\
Outliers & 0 \\
&
\end{tabular}

to the formation of a 'daisy-chain' like arrangement of ligands and metal ions, (Fig. 3B). The coordination sphere is completed by a carboxylate from an N-terminal glutamic acid (Glu2) of a symmetry-related molecule, (Fig. 3C); such a phenomenon has been observed for other helical metallopeptides. ${ }^{46}$ Combined, these ligands form a distorted tetrahedral coordination sphere around the $\mathrm{Cu}(\mathrm{II})$ ion, (Fig. 3C); bond lengths and angles are provided in Table S1.†

\section{The HisAD-Ni(II) complex is the most thermodynamically stable}

To probe the thermodynamic properties of the peptide:metal complexes, $\mathrm{Cu}$ (II) or $\mathrm{Ni}$ (II) were titrated into a solution of HisAD and the change in secondary structure of the peptide was monitored by CD spectroscopy. Fitting of these titration data allows binding energies and dissociation constants of the complexes to be determined.

Titrations with $\mathrm{Cu}$ (II) or $\mathrm{Ni}$ (II) both resulted in the same trend; an increase in helicity was observed as the amount of metal added to the peptide solution increased, with maximal binding being observed around a 1:1 peptide:metal ratio, (Fig. 4A \& B), which reflects the stoichiometry of the HisAD$\mathrm{Cu}$ (II) crystal structure. The $1: 1$ HisAD-Ni(II) complex was more folded than HisAD-Cu(II), $\left(-19,701 \mathrm{deg} \mathrm{cm}^{2} \mathrm{dmol} \mathrm{res}^{-1}\right.$ and $-13758 \mathrm{deg} \mathrm{cm}^{2} \mathrm{dmol} \mathrm{res}^{-1}$ respectively), which indicates that $\mathrm{Ni}(\mathrm{II})$ is more stabilising than $\mathrm{Cu}$ (II). This was supported by analysis of thermal unfolding data that determined the melting temperature $\left(T_{\mathrm{M}}\right)$ at $100 \mu \mathrm{M}$ of the HisAD-Cu(II) complex to be $32{ }^{\circ} \mathrm{C}$, whereas HisAD-Ni(II) had a $T_{\mathrm{M}}$ of $45{ }^{\circ} \mathrm{C}$, (Fig. S12†). It should be noted that both these metallopeptide complexes are less stable that CC-Tri, the peptide HisAD is based on, as CC-tri does not completely unfold, even at elevated temperatures. ${ }^{4}$

Titrations were also performed with both $\mathrm{Co}(\mathrm{II})$ and $\mathrm{Zn}$ (II) to investigate whether folding of HisAD could be induced at elevated concentrations of these metals. Addition of $\mathrm{Zn}$ (II) at increasing concentrations failed to induce any helical structure of HisAD, even when $\mathrm{Zn}$ (II) was present in a three-fold molar excess, (Fig. S13A $\dagger$ ). Interestingly, while a sub-stoichiometric ratio of $\mathrm{Co}(\mathrm{II})$ failed to induce helicity in HisAD; addition of an excess of the metal resulted in a helical structure being observed, (Fig. S13B †). This large excess of $\mathrm{Co}(\mathrm{II})$ which is required to induce a helical structure indicates that the affinity of HisAD for $\mathrm{Co}(\mathrm{II})$ is weak.

To quantify the thermodynamic properties of the $\mathrm{Cu}(\mathrm{II})$ and $\mathrm{Ni}(\mathrm{II})$-containing complexes, titrations at different HisAD concentrations were performed, (Fig. S14 $\dagger$ ). As the X-ray crystal structure of the HisAD : $\mathrm{Cu}(\mathrm{II})$ complex revealed a $1: 1$ binding stoichiometry, a two-state model of $\mathrm{P}_{3} \mathrm{M}_{3}$ (three peptide chains and three metal ions) dissociation was fitted to the data, (Fig. S15 $\dagger$ ). However, this model failed to describe the observed ellipticity at intermediate metal concentrations $(<50 \mu \mathrm{M})$ with reasonable physical parameters. Thus, it was concluded that an intermediate state with a HisAD:metal stoichiometric ratio $>1$ must form first and a three-state model was therefore devised, eqn (1):

$$
\mathrm{P}_{3} \mathrm{M}_{3} \stackrel{K_{\mathrm{D} 3}}{\leftrightarrow} \mathrm{P}_{\rho} \mathrm{M}_{\mu}+(3-\rho) \mathrm{P}+(3-\mu) \mathrm{M} \stackrel{K_{\mathrm{Di}}}{\leftrightarrow} 3 \mathrm{P}+3 \mathrm{M}
$$

The intermediate state is represented by the notation, $\mathrm{P}_{\rho} \mathrm{M}_{\mu}$, where $\rho$ represents the number of peptide chains and $\mu$ the number of metal ions.

Models where $(\mu<\rho, \mu \leq 3, \rho \leq 2)$ were tested and compared, (Fig. $4 \mathrm{C}$ and D, S16 and S17†). The three-state model that best fitted the titration data for both $\mathrm{Cu}$ (II) and $\mathrm{Ni}(\mathrm{II})$ complexes was with a $\mathrm{P}_{3} \mathrm{M}_{1}$ intermediate, (Fig. $4 \mathrm{C}$ and D), and from these data thermodynamic properties could be determined, (Table 3). The lower $K_{\mathrm{D}}$ 's of the HisAD-Ni(II) complexes, coupled with the more favourable free energies, indicated their increased stability with respect to the HisAD-Cu(II) assemblies, which is consistent with the thermal unfolding data.

The notion that these complexes form via a $\mathrm{P}_{3} \mathrm{M}_{1}$ intermediate state is intriguing, and suggests a subtle interplay between the overall stability of the complex, the binding preferences of metal ions, and the peptide folding. The $\mathrm{P}_{3} \mathrm{M}_{1}$ intermediates are reasonably stable, as evidenced by the $\mu \mathrm{M}$ dissociation constants, however the overall $K_{\mathrm{D}}$ of the $\mathrm{P}_{3} \mathrm{M}_{3}$ assembly is reduced by several orders of magnitude; reflected in the increased dissociation enthalpies. This indicates that incorporation of two additional $\mathrm{Cu}(\mathrm{II})$ or $\mathrm{Ni}(\mathrm{II})$ ions results in a substantial energy gain of $\sim 50-55 \mathrm{~kJ} \mathrm{~mol}^{-1}$. What remains unclear is how the metal coordination changes from the $\mathrm{P}_{3} \mathrm{M}_{1}$ intermediate to the final $\mathrm{P}_{3} \mathrm{M}_{3}$ complex. It is hypothesised that the large energy gain is not only due to the complexation of two additional metal ions, but also to an alteration of the coordination geometry. No crystal structure of the $\mathrm{P}_{3} \mathrm{M}_{1}$ complex is available, but it is reasonable to assume that the metal ion is at 

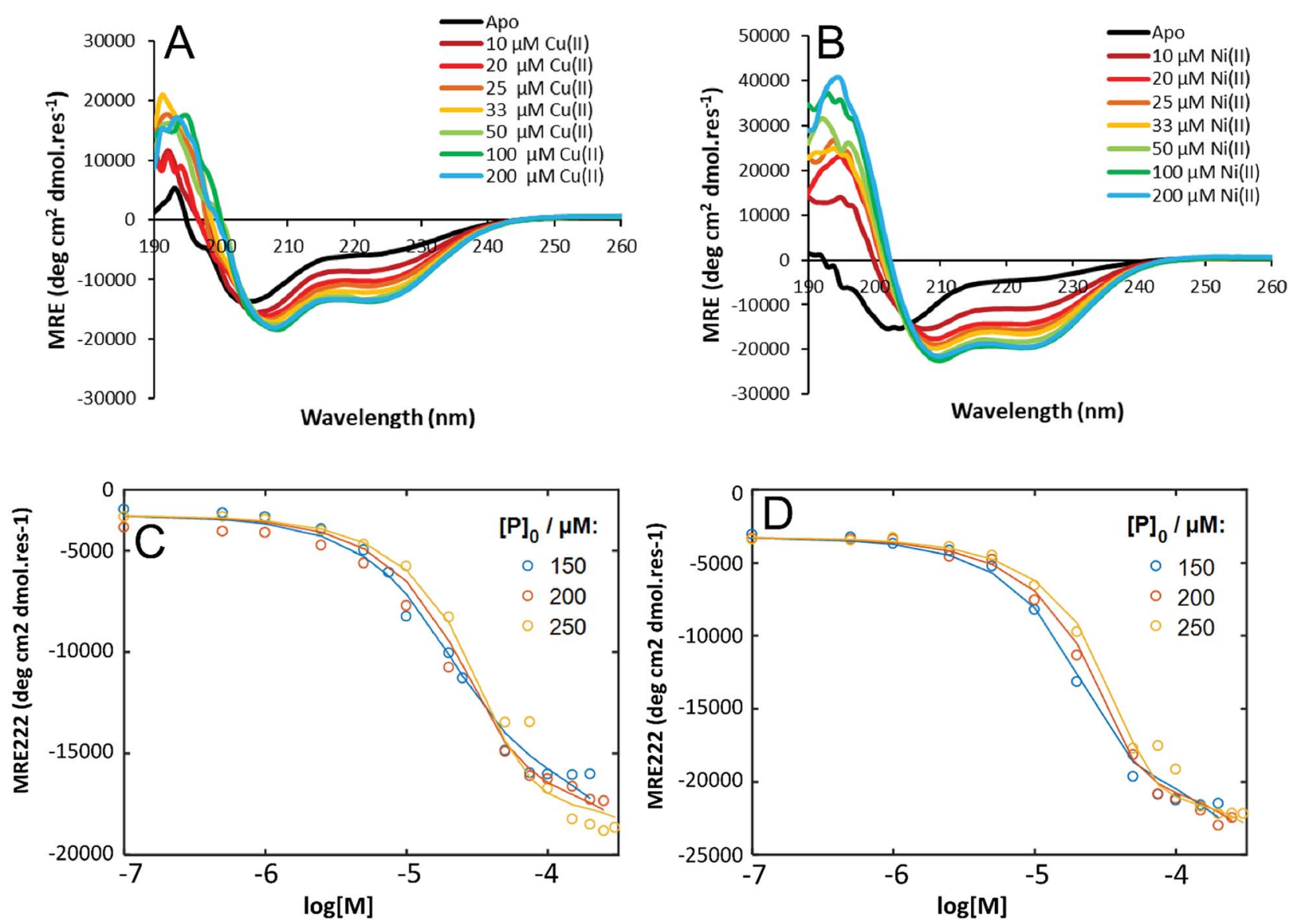

Fig. $4 \mathrm{CD}$ titration data for HisAD with $\mathrm{CU}(\|)$ and Ni(॥). CD spectra of (A) HisAD-Cu(॥), and; (B) HisAD-Ni(॥) with increasing amounts of the respective metal. A transition from a largely unfolded to a helical state is observed. Experimental data (dots) and fitted data (lines) for a three-state model for (C) HisAD-Cu(॥) and; (D) HisAD-Ni(॥). Conditions for (A) and (B): [peptide] = $100 \mu \mathrm{M}, 10 \mathrm{mM}$ phosphate buffer, pH 7.4, $20{ }^{\circ} \mathrm{C}$.

Table 3 Thermodynamic properties of the $\mathrm{Cu}(॥)$ and Ni(॥) complexes

\begin{tabular}{lcc}
\hline Peptide Complex & $\Delta G_{\mathrm{f}}\left(\mathrm{kJ} \mathrm{mol}^{-1}\right)^{a}$ & ${ }^{a} K_{\mathrm{d}}(\mu \mathrm{M})$ \\
\hline HisAD $: \mathrm{Cu}(\mathrm{II}) 3: 1$ & $-69.8 \pm 2.9$ & 71.8 \\
HisAD $: \mathrm{Cu}(\mathrm{II}) 3: 3$ & $-120.0 \pm 8.0$ & 0.075 \\
HisAD $: \mathrm{Ni}(\mathrm{II}) 3: 1$ & $-75.9 \pm 6.3$ & 30.9 \\
HisAD $:$ Ni(II) $3: 3$ & $-131.7 \pm 17.8$ & 0.015
\end{tabular}

${ }^{a}$ Both dissociation enthalpies and dissociation constants are obtained from fitting the titration data to the three-state model described above; a detailed explanation of the fitting procedure is provided is the ESI, along with the associated equations.

the centre of the coiled coil and is complexed by some, or all, of the His residues. There is a literature precedent for such a coordination mode. ${ }^{31,35,36,47}$ In this arrangement the central metal would be unavailable for complexation by Glu16. It is therefore assumed that the additional complexation by the Glu residues contributes significantly to the increased stability of the trinuclear complex with respect to the mononuclear assembly. Indeed, Kuhlman et al. discovered that, when computationally designing binding sites for transition metal ions comprising multiple histidine residues, complexation by glutamic acid residues was preferred in one of the positions. ${ }^{46}$ The patterning of the histidine and glutamic acid residues in HisAD therefore favours this unusual trinuclear coordination over preserving the coiled-coil packing. This is evident from the thermodynamic data, which shows binding of three metal ions is more stabilising than binding one ion, and this increased binding energy compensates for the loss of knobs-into-holes packing.

\section{Conclusions}

Here we have presented the first example of an $\alpha$-helical peptide, based on a coiled-coil scaffold, which binds three metal ions in identical coordination environments. Moreover, this peptide exhibits an unprecedented selectivity between different transition metal ions. We hypothesise that the reason for this selectivity is not due to ligand (i.e. hard versus soft) or coordination geometry preferences but is instead due to the relative stabilities of the resulting peptide-metal complexes. The IrvingWilliams series indicates that the most stable assembly should be formed with $\mathrm{Cu}$ (II), whereas we observe most stability with $\mathrm{Ni}(\mathrm{II})$, however the differences in binding energies for the two complexes is relatively small. Further fundamental studies will 
focus on probing the basis for this selectivity further, by generating peptide scaffolds with differing stabilities and investigating the effects on metal binding. The metal-binding selectivity displayed by HisAD will be exploited to generate metal-ion sensing devices. Additionally, the HisAD-Cu(II) assembly will be used as a starting point for the generation of mimics of complex multi-copper containing enzymes; the fact that this assembly already coordinates multiple metal ions provides a distinct advantage over other metallopeptide structures in the realisation of this goal. These enzyme mimics will subsequently be evaluated for their electron transfer properties; the presence of multiple metal ions may allow for the simultaneous transfer of multiple electrons or for an enhanced transfer rate.

\section{Experimental}

\section{General experimental information}

Dimethylformamide (DMF), piperidine, acetic anhydride, pyridine, trifluoroacetic acid (TFA) and acetonitrile (MeCN) were purchased from Biosolve. $N, N$-diisopropylethylamine (DIPEA), and Oxyma were obtained from Carl Roth. Dichloromethane (DCM) and diethyl ether were supplied by Honeywell. Tentagel HL-RAM was obtained from Rapp Polymere. All amino acids were supplied by NovaBioChem. All other chemicals were purchased from Sigma Aldrich. Ultrapure water was obtained from a MILLI-Q ${ }^{\mathrm{TM}}$ purification system. All buffers were made at pH 7.4 unless otherwise stated.

\section{Peptide synthesis and purification}

Peptides were synthesized using a Liberty Blue, microwaveassisted, automated peptide synthesizer. Synthesis was performed on the solid-phase, at a $0.1 \mathrm{mmol}$ scale, using Tentagel HL-RAM resin. Fmoc-deprotection was achieved using 20\% piperidine in DMF, and coupling was facilitated with DIC as activator and Oxyma as base. Upon completion of synthesis, peptides were manually acetylated using acetic anhydride and pyridine, before cleavage from the resin was performed using a mixture of TFA : TIPS : water, $95: 2.5: 2.5$. The peptide was precipitated using ice-cold diethyl ether; the precipitate was subsequently collected by centrifugation before being resuspended in a water and MeCN mixture and freeze-dried.

Purification was performed by reversed-phase HPLC on a Kinetic Evo C18 column with a Shimadzu system comprising two LC-8A pumps and an SPD-10AVP UV-vis detector. All peptides were purified using a gradient of $20-80 \% \mathrm{~B}$, (where $\mathrm{B}$ is MeCN containing $0.1 \%$ TFA, and A is water with $0.1 \%$ TFA) over 20 minutes with a flow rate of $12 \mathrm{ml} \mathrm{min}^{-1}$. The collected fractions were analysed using LCMS, Fig. S18-22, $\dagger$ and those deemed to be $>95 \%$ pure were pooled and freeze-dried.

\section{Circular dichroism spectroscopy}

CD spectra were measured using a JASCO-J815 spectrometer fitted with a Peltier temperature controller. Quartz cuvettes with a $1 \mathrm{~mm}$ path length were used for all measurements. Spectra were recorded at $20^{\circ} \mathrm{C}$ from $260-190 \mathrm{~nm}$, at $1 \mathrm{~nm}$ intervals, with a scanning speed of $100 \mathrm{~nm} \mathrm{~min}{ }^{-1}$, a response rate of $1 \mathrm{~s}$, and a bandwidth of $1 \mathrm{~nm}$. Spectra were averaged over 5 scans.

Melt spectra were monitored at $222 \mathrm{~nm}$, between 5 and $95^{\circ} \mathrm{C}$, with a heating rate of $40{ }^{\circ} \mathrm{C} \mathrm{h}^{-1}$, and a data point was recorded every $1{ }^{\circ} \mathrm{C}$. Melting temperatures were obtained by taking the second derivative of the melting curve.

All data was converted to mean residue ellipticity, $[\theta]$, using eqn (2):

$$
[\theta]=\frac{100 \times[\theta]_{\mathrm{obs}}}{C \times n \times l}
$$

Here, $[\theta]_{\text {obs }}$ is the observed ellipticity (mdeg), $C$ is the peptide concentration (mM), $n$ is the number of peptide bonds, and $l$ is the pathlength of the cuvette $(\mathrm{cm})$.

For fitting of the 3-state model the dissociation constants of the partial reactions $K_{\mathrm{Di}}$ and $K_{\mathrm{D} 3}$ from eqn (1) can be expressed as eqn (3) and (4) (cf. ESI eqn. (1)-(11) $\dagger)$ :

$$
\begin{gathered}
K_{\mathrm{Di}}=\frac{\rho\left(P_{0}\left(1-\alpha_{3}-\alpha_{\mathrm{i}}\right)\right)^{\rho}\left(M_{0}-P_{0} \alpha_{3}-\frac{\mu}{\rho} P_{0} \alpha_{\mathrm{i}}\right)^{\mu}}{P_{0} \alpha_{\mathrm{i}}} \\
K_{\mathrm{D} 3}=\frac{3 \alpha_{\mathrm{i}}\left(P_{0}\left(1-\alpha_{3}-\alpha_{\mathrm{i}}\right)\right)^{3-\rho}\left(M_{0}-P_{0} \alpha_{3}-\frac{\mu}{\rho} P_{0} \alpha_{\mathrm{i}}\right)^{3-\mu}}{\rho \alpha_{3}}
\end{gathered}
$$

Here $\mathbf{M}_{0}$ and $\mathrm{P}_{0}$ are the metal and peptide concentrations respectively, $\rho$ is the number of peptide chains, $\mu$ is the number of metal ions, and $\alpha_{3}$ and $\alpha_{\mathrm{i}}$ stand for the fraction of peptide chains bound in the $\mathrm{P}_{3} \mathrm{M}_{3}$ complex and the intermediate, respectively. Eqn (3) and (4) are treated as a system of nonlinear equations and the solutions for the two unknowns $\alpha_{i}$ and $\alpha_{3}$ were determined using the MATLAB Symbolic Math Toolbox as described in detail in the ESI. $\dagger$

Fit parameters were $\mathrm{p} K_{\mathrm{D} 3}, \mathrm{p} K_{\mathrm{Di}},\left(\mathrm{p} K_{\mathrm{Di}, \mathrm{D} 3}=-\log _{10} K_{\mathrm{Di}, \mathrm{D} 3}\right)$ and the mean residual ellipticities at $222 \mathrm{~nm}$ for $100 \%$ folded as $\mathrm{P}_{3} \mathrm{M}_{3}\left([\theta]_{\mathrm{s} 3}\right)$ and $P_{(3-\rho)} M_{(3-\mu)}\left([\theta]_{\mathrm{si}}\right)$, (cf. ESI eqn (4)†) respectively. From the fit parameters the free energy of folding per peptide chain was determined by eqn (5):

$$
\Delta G_{\mathrm{f}}=\left(-\mathrm{p} K_{\mathrm{D}}\right) R T \ln 10
$$

with the absolute temperature $T$, the gas constant $R$, and $\mathrm{p} K_{\mathrm{D}}=$ $\mathrm{p} K_{\mathrm{Di}}$ for the $\mathrm{P}_{3} \mathrm{M}_{1}$ complex and $\mathrm{p} K_{\mathrm{D}}=\mathrm{p} K_{\mathrm{Di}}+\mathrm{p} K_{\mathrm{D} 3}$ for the trinuclear assembly. The dissociation constant, $K_{\mathrm{d}}$, referring to one equivalent of peptide chains is given by eqn (6):

$$
K_{\mathrm{d}}=10^{-\frac{\mathrm{p} K_{\mathrm{D}}}{3}}
$$

\section{Analytical ultracentrifugation}

AUC sedimentation equilibrium experiments were conducted at $20{ }^{\circ} \mathrm{C}$ in a Beckman ProteomeLab XL-I or XL-A analytical ultracentrifuge using an An-50 or An-60 Ti rotor (Beckmann Coulter). Solutions were made at $200 \mu \mathrm{M}$ peptide concentration, in PBS, pH 7.4, with $100 \mathrm{mM} \mathrm{NaCl}$ to provide sufficient chargeparing ions. The experiments were run in triplicate in sixchannel centrepieces. The samples were centrifuged at speeds 
in the range $30-48 \mathrm{k}$ rpm in $3 \mathrm{k} \mathrm{rpm}$ intervals and scans at each recorded speed were duplicated. Data were fitted to single idealspecies models using Ultrascan II, (http:/ www.ultrascan.uthscsa.edu), comprising a minimum of four speeds. 95\% confidence limits were obtained via Monte Carlo analysis of the obtained fits.

Sedimentation-velocity experiments were conducted at $20^{\circ} \mathrm{C}$ in a Beckman ProteomeLab XL-A or Beckman ProteomeLab XL-I analytical ultracentrifuge using an An-60 Ti rotor. Solutions of $310 \mu \mathrm{l}$ volume were made at $200 \mu \mathrm{M}$ peptide concentration and placed in a sedimentation-velocity cell with an epon twochannel centrepiece and quartz windows. The reference channel was loaded with $325 \mu$ l of buffer. The samples were centrifuged at $60 \mathrm{k} \mathrm{rpm}$, with absorbance scans taken across a radial range of 5.8 to $7.3 \mathrm{~cm}$ at $5 \mathrm{~min}$ intervals to a total of 120 scans. Data from a single run were fitted to a continuous c(s) distribution model using Sedfit, ${ }^{48}$ at $95 \%$ confidence level. The partial specific volume $(\vec{\nu})$ for the peptide and the buffer densities and viscosities were calculated using Ultrascan II (http:/www.ultrascan.uthscsa.edu).

\section{NMR spectroscopy}

Samples were prepared in water at $500 \mu \mathrm{M}$ peptide concentration, with 0 or 1 equivalent of $\mathrm{Cu}(\mathrm{II})$ or $\mathrm{Ni}(\mathrm{II})$. The samples were freeze dried and redissolved in $10 \mathrm{mM}$ phosphate buffer, prepared in $\mathrm{D}_{2} \mathrm{O}$. NMR spectra were recorded at ambient temperature $(298 \mathrm{~K})$ using a Bruker Avance $500 \mathrm{MHz}$ spectrometer equipped with a Bruker BBFO probe. Spectra were recorded using a standard pulse sequence with HDO presaturation for 512, or 1024 scans, when the sample contained higher metal concentrations. ${ }^{1} \mathrm{H}$ chemical shifts $(\delta)$ were reported relative to the residual solvent peak ( $\delta 4.79 \mathrm{ppm}$ ). Data processing and analysis was performed using MestReNova with manual peak assignment and integration.

\section{X-ray crystallography: crystallization}

The peptide solution was prepared at a concentration of $15 \mathrm{mg}$ $\mathrm{mL}^{-1}$, with 1 equivalent of $\mathrm{Cu}(\mathrm{II})$ in ultrapure water. Crystallization was achieved using the sitting-drop vapour-diffusion method at $20{ }^{\circ} \mathrm{C}$. Initial screens were performed using the commercially available PACT premier and JCSG+ screens from Molecular Dimensions. Initial crystallization plates were prepared using an NT8 robot (Formulatrix) for pipetting the reservoir solution $(70 \mu \mathrm{L})$ and making the drops $(500 \mathrm{~nL})$. Crystals were seen in many conditions, but the largest were in JCSG+, condition D7 (0.2 $\mathrm{M} \mathrm{LiSO}_{4}, 0.1 \mathrm{M}$ TRIS $8.5 \mathrm{pH}, 40 \% \mathrm{v} / \mathrm{v}$ PEG 400). This condition was further optimized by varying the concentration of the buffer, precipitant and salt as well as employing an additive screen. Crystals giving the best diffraction grew in $\sim 1$ month in $0.09 \mathrm{M}$ TRIS pH 8.5, $0.18 \mathrm{M} \mathrm{LiSO}_{4}$, $36 \% \mathrm{v} / \mathrm{v}$ PEG 400 and 5\% v/v Jeffamine M-600. The crystals were mounted on cryo-loops and, before flash-cooling in liquid nitrogen, were cryo-protected in a solution consisting of mother liquor and $15 \% \mathrm{v} / \mathrm{v}$ glycerol.

\section{$X$-ray crystallography: data collection and refinement}

X-ray data collection was performed at the European Synchrotron Radiation Facility (ESRF, Grenoble, France) on beamline ID30B, ${ }^{49}$ at a wavelength tuned to 1.34765 Angstroms to optimize the anomalous signal from the intrinsic copper atoms. The data sets were auto-processed by the EDNA auto-processing package that used $\mathrm{XDS}^{50}$ to integrate the intensities and AIMLESS $^{51}$ to scale and merge the intensities. The diffraction patterns indicated severe anisotropy that was evident in the merging statistics that showed weaker diffraction along the h-k plane. Although the anomalous signal was large (as judged by the anomalous correlation coefficient), all attempts to solve the structure from the anomalous signal alone failed. A molecular replacement solution was found using ARCIMOBOLDO, ${ }^{52-55}$ and this model was further built with CRANK2. ${ }^{56}$ The model was further refined with iterative manual model building using REFMAC,$^{57}$ and COOT, ${ }^{58}$ from the CCP4 suite. ${ }^{59}$ Given the very small size of the data set, all the data was used in the refinement and to prevent overfitting, 'jelly-body' refinement within REFMAC was used. In order to validate the final model, the $R$ complete $^{60}$ was used. The final $R$-complete and $R$-work were $25.5 \%$, and $26.7 \%$ respectively. The data collection and refinement statistics are presented in Table 2 and the final coordinates have been deposited in the protein data bank, PDB code: $6 \mathrm{I} 1 \mathrm{~J}$.

\section{Conflicts of interest}

There are no conflicts to declare.

\section{Acknowledgements}

The X-ray data collection was performed on beamline ID30-B at the European Synchrotron Radiation Facility (ESRF), Grenoble, France. We are grateful to Alexander Popov at the ESRF for providing assistance using beamline ID30-B. The work was supported by the NWO via a VENI grant (722.015.006) to ALB. MR acknowledges funding from the European Union's Horizon 2020 research and innovation programme through a Marie Skłodowska-Curie Grant (Agreement No. 705857). A VICI grant (724.014.001) awarded to AK funded NSAC. GGR is supported by a European Research Council Advanced Grant (340764). NSP acknowledges the support of an NWO ZonMW grant (91116025). NS acknowledges grant number BIO2015-64216-P (MINECO/AEI/FEDER/UE).

\section{References}

1 F. H. C. Crick, Acta Crystallogr., 1953, 6, 689-697.

2 A. N. Lupas and M. Gruber, Fibrous Proteins: Coiled-Coils, Collagen and Elastomers, 2005, vol. 70, pp. 37-78.

3 D. N. Woolfson, Fibrous Proteins: Coiled-Coils, Collagen and Elastomers, 2005, vol. 70, pp. 79-112.

4 J. M. Fletcher, A. L. Boyle, M. Bruning, G. J. Bartlett, T. L. Vincent, N. R. Zaccai, C. T. Armstrong, 
E. H. C. Bromley, P. J. Booth, R. L. Brady, A. R. Thomson and D. N. Woolfson, ACS Synth. Biol., 2012, 1, 240-250.

5 P. B. Harbury, T. Zhang, P. S. Kim and T. Alber, Science, 1993, 262, 1401-1407.

6 G. R. Dieckmann, D. K. McRorie, D. L. Tierney, L. M. Utschig, C. P. Singer, T. V. Ohalloran, J. E. PennerHahn, W. F. DeGrado and V. L. Pecoraro, J. Am. Chem. Soc., 1997, 119, 6195-6196.

7 D. Ghosh and V. L. Pecoraro, Inorg. Chem., 2004, 43, 79027915.

8 D. Ghosh and V. L. Pecoraro, Curr. Opin. Chem. Biol., 2005, 9, 97-103.

9 S. Chakraborty, J. Y. Kravitz, P. W. Thulstrup, L. Hemmingsen, W. F. DeGrado and V. L. Pecoraro, Angew. Chem., Int. Ed., 2011, 50, 2049-2053.

10 J. S. Plegaria, S. P. Dzul, E. R. P. Zuiderweg, T. L. Stemmler and V. L. Pecoraro, Biochemistry, 2015, 54, 2858-2873.

11 K. J. Koebke, L. Ruckthong, J. L. Meagher, E. Mathieu, J. Harland, A. Deb, N. Lehnert, C. Policar, C. Tard, J. E. Penner-Hahn, J. A. Stuckey and V. L. Pecoraro, Inorg. Chem., 2018, 57, 12291-12302.

12 J. S. Plegaria, M. Duca, C. Tard, T. J. Friedlander, A. Deb, J. E. Penner-Hahn and V. L. Pecoraro, Inorg. Chem., 2015, 54, 9470-9482.

13 S. T. R. Walsh, H. Cheng, J. W. Bryson, H. Roder and W. F. DeGrado, Proc. Natl. Acad. Sci. U. S. A., 1999, 96, 5486-5491.

14 K. Suzuki, H. Hiroaki, D. Kohda, H. Nakamura and T. Tanaka, J. Am. Chem. Soc., 1998, 120, 13008-13015.

15 D. Shiga, D. Nakane, T. Inomata, H. Masuda, M. Oda, M. Noda, S. Uchiyama, K. Fukui, Y. Takano, H. Nakamura, T. Mizuno and T. Tanaka, Biopolymers, 2009, 91, 907-916.

16 O. A. Kharenko and M. Y. Ogawa, J. Inorg. Biochem., 2004, 98, 1971-1974.

17 J. Aupic, F. Lapenta and R. Jerala, ChemBioChem, 2018, 19, 2453-2457.

18 S. Studer, D. A. Hansen, Z. L. Pianowski, P. R. E. Mittl, A. Debon, S. L. Guffy, B. S. Der, B. Kuhlman and D. Hilvert, Science, 2018, 362, 1285-1288.

19 M. R. Berwick, D. J. Lewis, A. W. Jones, R. A. Parslow, T. R. Dafforn, H. J. Cooper, J. Wilkie, Z. Pikramenou, M. M. Britton and A. F. A. Peacock, J. Am. Chem. Soc., 2014, 136, 1166-1169.

20 M. Chino, L. Leone, O. Maglio, D. D'Alonzo, F. Pirro, V. Pavone, F. Nastri and A. Lombardi, Angew. Chem., Int. Ed., 2017, 56, 15580-15583.

21 M. Faiella, C. Andreozzi, R. T. M. de Rosales, V. Pavone, O. Maglio, F. Nastri, W. F. DeGrado and A. Lombardi, Nat. Chem. Biol., 2009, 5, 882-884.

22 A. Lombardi, C. M. Summa, S. Geremia, L. Randaccio, V. Pavone and W. F. DeGrado, Proc. Natl. Acad. Sci. U. S. A., 2000, 97, 6298-6305.

23 A. Pasternak, S. Kaplan, J. D. Lear and W. F. DeGrado, Protein Sci., 2001, 10, 958-969.

24 S. Q. Zhang, M. Chino, L. J. Liu, Y. Z. Tang, X. Z. Hu, W. F. DeGrado and A. Lombardi, J. Am. Chem. Soc., 2018, 140, 1294-1304.
25 T. L. Olson, E. Espiritu, S. Edwardraja, E. Canarie, M. Flores, J. C. Williams, G. Ghirlanda and J. P. Allen, Biochim. Biophys. Acta, Bioenerg., 2017, 1858, 945-954.

26 M. Flores, T. L. Olson, D. Wang, S. Edwardraja, S. Shinde, J. C. Williams, G. Ghirlanda and J. P. Allen, J. Phys. Chem. B, 2015, 119, 13825-13833.

27 D. Shiga, Y. Funahashi, H. Masuda, A. Kikuchi, M. Noda, S. Uchiyama, K. Fukui, K. Kanaori, K. Tajima, Y. Takano, H. Nakamura, M. Kamei and T. Tanaka, Biochemistry, 2012, 51, 7901-7907.

28 O. A. Kharenko, D. C. Kennedy, B. Demeler, M. J. Maroney and M. Y. Ogawa, J. Am. Chem. Soc., 2005, 127, 7678-7679.

29 D. V. Zaytsev, V. A. Morozov, J. F. Fan, X. C. Zhu, M. Mukherjee, S. S. Ni, M. A. Kennedy and M. Y. Ogawa, J. Inorg. Biochem., 2013, 119, 1-9.

30 A. Roy, I. Sarrou, M. D. Vaughn, A. V. Astashkin and G. Ghirlanda, Biochemistry, 2013, 52, 7586-7594.

31 T. Tanaka, T. Mizuno, S. Fukui, H. Hiroaki, J. Oku, K. Kanaori, K. Tajima and M. Shirakawa, J. Am. Chem. Soc., 2004, 126, 14023-14028.

32 M. L. Zastrow, A. F. A. Peacock, J. A. Stuckey and V. L. Pecoraro, Nat. Chem., 2012, 4, 118-123.

33 M. L. Zastrow and V. L. Pecoraro, J. Am. Chem. Soc., 2013, 135, 5895-5903.

34 P. Teare, C. F. Smith, S. J. Adams, S. Anbu, B. Ciani, L. J. C. Jeuken and A. F. A. Peacock, Dalton Trans., 2018, 47, 10784-10790.

35 S. N. Dublin and V. P. Conticello, J. Am. Chem. Soc., 2008, 130, 49-51.

36 T. Kiyokawa, K. Kanaori, K. Tajima, M. Koike, T. Mizuno, J. I. Oku and T. Tanaka, J. Pept. Res., 2004, 63, 347-353.

37 M. Matzapetakis and V. L. Pecoraro, J. Am. Chem. Soc., 2005, 127, 18229-18233.

38 J. M. Fletcher, G. J. Bartlett, A. L. Boyle, J. J. Danon, L. E. Rush, A. N. Lupas and D. N. Woolfson, ACS Chem. Biol., 2017, 12, 528-538.

39 S. Barber-Zucker, B. Shaanan and R. Zarivach, Sci. Rep., 2017, 7, 16381.

40 L. Rulisek and J. Vondrasek, J. Inorg. Biochem., 1998, 71, 115127.

41 H. Irving and R. J. P. Williams, J. Chem. Soc., 1953, 31923210, DOI: $10.1039 /$ jr9530003192.

42 I. Bertini, P. Turano and A. J. Vila, Chem. Rev., 1993, 93, 2833-2932.

43 G. R. Dieckmann, D. K. McRorie, J. D. Lear, K. A. Sharp, W. F. DeGrado and V. L. Pecoraro, J. Mol. Biol., 1998, 280, 897-912.

44 M. V. Tsurkan and M. Y. Ogawa, Inorg. Chem., 2007, 46, 6849-6851.

45 J. Walshaw and D. N. Woolfson, J. Mol. Biol., 2001, 307, 1427-1450.

46 B. S. Der, M. Machius, M. J. Miley, J. L. Mills, T. Szyperski and B. Kuhlman, J. Am. Chem. Soc., 2012, 134, 375-385.

47 M. Tegoni, F. T. Yu, M. Bersellini, J. E. Penner-Hahn and V. L. Pecoraro, Proc. Natl. Acad. Sci. U. S. A., 2012, 109, 21234-21239.

48 P. Schuck, Biophys. J., 2000, 78, 1606-1619. 
49 A. A. McCarthy, R. Barrett, A. Beteva, H. Caserotto, F. Dobias, F. Felisaz, T. Giraud, M. Guijarro, R. Janocha, A. Khadrouche, M. Lentini, G. A. Leonard, M. L. Marrero, S. Malbet-Monaco, S. McSweeney, D. Nurizzo, G. Papp, C. Rossi, J. Sinoir, C. Sorez, J. Surr, O. Svensson, U. Zander, F. Cipriani, P. Theveneau and C. Mueller-Dieckmann, J. Synchrotron Radiat., 2018, 25, 1249-1260.

50 W. Kabsch, Acta Crystallogr., Sect. D: Biol. Crystallogr., 2010, 66, 133-144.

51 P. R. Evans and G. N. Murshudov, Acta Crystallogr., Sect. D: Biol. Crystallogr., 2013, 69, 1204-1214.

52 I. Caballero, M. Sammito, C. Millan, A. Lebedev, N. Soler and I. Uson, Acta Crystallogr., Sect. D: Struct. Biol., 2018, 74, 194204.

53 A. J. Mccoy, R. W. Grosse-Kunstleve, P. D. Adams, M. D. Winn, L. C. Storoni and R. J. Read, J. Appl. Crystallogr., 2007, 40, 658-674.

54 D. D. Rodriguez, C. Grosse, S. Himmel, C. Gonzalez, I. M. de Ilarduya, S. Becker, G. M. Sheldrick and I. Uson, Nat. Methods, 2009, 6, 651-U639.
55 I. Uson and G. M. Sheldrick, Acta Crystallogr., Sect. D: Struct. Biol., 2018, 74, 106-116.

56 P. Skubak and N. S. Pannu, Nat. Commun., 2013, 4, 2777.

57 G. N. Murshudov, P. Skubak, A. A. Lebedev, N. S. Pannu, R. A. Steiner, R. A. Nicholls, M. D. Winn, F. Long and A. A. Vagin, Acta Crystallogr., Sect. D: Biol. Crystallogr., 2011, 67, 355-367.

58 P. Emsley, B. Lohkamp, W. G. Scott and K. Cowtan, Acta Crystallogr., Sect. D: Biol. Crystallogr., 2010, 66, 486-501.

59 M. D. Winn, C. C. Ballard, K. D. Cowtan, E. J. Dodson, P. Emsley, P. R. Evans, R. M. Keegan, E. B. Krissinel, A. G. W. Leslie, A. McCoy, S. J. McNicholas, G. N. Murshudov, N. S. Pannu, E. A. Potterton, H. R. Powell, R. J. Read, A. Vagin and K. S. Wilson, Acta Crystallogr., Sect. D: Biol. Crystallogr., 2011, 67, 235-242.

60 J. Luebben and T. Gruene, Proc. Natl. Acad. Sci. U. S. A., 2015, 112, 8999-9003. 